\title{
Geotechnical data - a strategic or tactical issue?
}

\author{
M.J. Dunn Newmont Asia Pacific, Australia \\ F.R. Basson Newmont Asia Pacific, Australia
}

T.T. Parrott Newmont Asia Pacific, Australia

\section{Abstract}

Newmont uses a Stage-Gate approach to developing mining projects which takes a project from scoping (Stage 1) through to implementation (Stage 5). This is linked to the resource and reserve conversion process as well as confidence in mine designs and planning. The question of how much geotechnical data is needed at each stage often arises. Currently very little quantitative guidance exists in the literature although there have been attempts by various authors (Haile, 2004; Haines et al., 2006; Read and Stacey, 2009) to qualitatively describe what level of geotechnical data is required.

Each mining project is different and the data collection program should be designed to reflect the orebody type, possible mining methods, appetite for uncertainty and the owners risk profile. In all cases a number of key questions need to be considered:

- How much data should be collected and timing of the data collection?

- What level of data collection is needed?

- What data collection standards should be used?

An approach has been developed that attempts to define what levels of geotechnical data are required to support the Stage-Gate process, and examples are provided from a number of recent mining studies.

\section{Introduction}

Geotechnical engineers working in the mining industry are regularly asked the question of how much geotechnical data is required for a mining project study or a geotechnical design. This question relates directly to confidence in geotechnical models and designs and geotechnical risks.

For this seminar the terms Strategic and Tactical are defined as follows:

- Strategic: mining focus to achieve long-term goals by proactively addressing potential industry risks, gaps and uncertainties.

- Tactical: mining focus to achieve short-term goals. The uncertain nature and inherent risks in mining tend to generate a reactive approach.

Often the approach to geotechnical data collection is tactical with the minimum being collected early on and additional data being collected when problems arise. This approach can also result in poor decisions being made in terms of mining method and geotechnical risks. To counteract the high level of uncertainty, conservative inputs are often used and conservative decisions are made. A strategic approach to geotechnical data collection will reduce uncertainties and allow better geotechnical decisions to be made and can also reduce conservatism in design.

\section{Overview}

Currently very little quantitative guidance exists in the literature on determining geotechnical data requirements, although there have been attempts by various authors (Steffen, 1997; Haile, 2004; Haines et 
al., 2006; Read and Stacey, 2009) to qualitatively describe what level of geotechnical data is required. This is quite different to the resource and reserve process in which data requirements are relatively well defined in various guidelines (e.g. JORC, SAMVAL).

Often geotechnical data collection programs are based heavily on qualitative guidelines and engineering judgement. When geotechnical engineers and mining companies make decisions about geotechnical data programs they are making a decision that will impact on the risks they are willing to accept. When engineering judgement is applied, the engineer is inferring and making a decision about what risk the owner is prepared to accept. A number of authors have tried to include this risk element in the qualitative guidance. A short overview of qualitative guidance available follows.

\section{1 West Australian guidelines}

The Department of Industry and Resources, now known as the Department of Mines and Petroleum (DMP), published a geotechnical considerations guideline for underground mines in 1997. This document suggests that the appropriate geotechnical data are collected from a representative number of cored bore holes, preferably oriented and suggested percentages are shown in Table 1.

Table 1 Suggested percentage of cored boreholes to be geotechnically logged (DoIR, 1997)

\begin{tabular}{lc}
\hline $\begin{array}{l}\text { Stage of Mine } \\
\text { Development }\end{array}$ & $\begin{array}{c}\text { Suggested Percentage of } \\
\text { Geotechnically Logged Holes }\end{array}$ \\
\hline Prefeasibility study & $25-50 \%$ \\
Feasibility study & $50-100 \%$ \\
Operating mine & $25-75 \%$ \\
\hline
\end{tabular}

The same organisation also published geotechnical guidelines for open pit mines in 1999. This document outlines the need to collect geotechnical data that is consistent with type, size and life of the open pit. It does not provide guidance in the same way as the underground geotechnical guidelines but does make reference to the requirements of regulation 13.8 (2) as follows:

Each responsible person at a mine must ensure that the following measures are taken in relation to ground control in the quarry -

- adequate consideration is given to local geological structure and its influence on wall stability;

- adequate consideration is given to shear strength of the rock mass and its geological structure. DolR (1999)

Both these guidelines are useful and outline requirements for a ground control management plan that includes a process for the collection of geotechnical data over the life of a mining project.

\section{2 Industry guidance and practice}

Steffen (1997) linked slope angles and the degree of design confidence based on the uncertainty of the underlying geotechnical data to the resource-reserve process and proposed the classification shown in Table 2. Whilst the Steffen (1997) paper focused on open pit mines, the concepts covered in the paper are also applicable to underground mines.

Haile (2004) proposed a geotechnical classification based on the structure of resource-reserve reporting codes. To avoid confusion with resource and reserve classifications he introduced the terms 'Implied', 'Qualified', 'Justified' and 'Verified' as described in Table 3. Qualitative guidance is provided for each classification in terms of its requirements for the geological model, rock mass data, defect data, stress regime, geotechnical domains and the hydrogeological model. 
Table 2 Geotechnical confidence classifications proposed by Steffen (1997)

$\begin{array}{ll}\text { Category } 1 \text { - proven slope angles } & \text { Geotechnical investigations carried out to a feasibility study } \\ \text { standard. In essence designs should have a minimum confidence } \\ \text { level of } 85 \% \text { requiring: } \\ \text { - continuity of stratigraphy and lithological units confirmed in } \\ \text { space through adequate intersections } \\ \text { - detailed structural mapping of rock fabric is implied } \\ \text { - strength characteristics of structural features and the rock mass } \\ \text { through appropriate testing } \\ \text { - } \text { ground water pressures have been measured. } \\ \text { Eategory 2 - probable slope angles to a design based on information that allows the following: } \\ \text { - reasonable assumptions on continuity of stratigraphy and } \\ \text { lithological units } \\ \text { - some structural mapping has been carried out and all major } \\ \text { features and joint sets should be identified } \\ \text { - limited rock testing for physical properties of the in-situ rock } \\ \text { and defects has been carried out } \\ \text { - preliminary groundwater analysis } \\ \text { - enough information gained to conduct simplified design models } \\ \text { with sensitivities. } \\ \text { Equates to an inferred design using limited geotechnical } \\ \text { investigations. Typical slope angles will be based on experience } \\ \text { verified with rock mass ratings and some inference to geological } \\ \text { conditions within the affected rock mass. }\end{array}$

Haile (2004) also provided qualitative guidance relating the geotechnical data requirements for different study stages through to operation to the mining method and orebody geometry. This approach factors in the geotechnical risk associated with different mining methods and orebodies (e.g. a wide shallow pit versus a deep narrow pit).

Haines et al. (2006) considered geotechnical data in terms of geotechnical risks and the need to reduce risk by having a better understanding of the geotechnical environment. They provide a summary of their experience of geotechnical drilling and logging conducted for various studies, from scoping through to feasibility level, expressed as a proportion of resource holes drilled (Table 4). Generally there is a doubling in the percentage of geotechnical holes as the study progresses. However, the values reported are significantly lower than suggested in the Western Australian Underground Guideline as in Section 2.1. 
Table 3 Geotechnical classification of mining projects (Haile, 2004)

Implied (inferred) $\quad \begin{aligned} & \text { Geotechnical model has a low level of reliability. } \\ & \text { Based on global estimates of geotechnical characteristics. } \\ & \text { Will enable only a limited scope of analysis, and development of only conceptual } \\ & \text { level, mine-wide design parameters. } \\ & \text { Variability or uncertainty in the geotechnical model could have a significant } \\ & \text { impact on the economic viability of the project. } \\ & \text { Qualified (indicated) } \\ & \text { Geotechnical model has a reasonable level of confidence. } \\ & \text { Provides a broad indication of the intrinsic spatial variability of the geotechnical } \\ & \text { characteristics. } \\ & \text { A reasonable scope of analysis could be applied, which broadly defines } \\ & \text { geotechnical domains, enabling the development of reasonably reliable, domain- } \\ & \text { specific design parameters. } \\ & \text { Variability or uncertainty in the geotechnical model could have a moderate } \\ & \text { impact on the economic viability of the project. } \\ & \text { Geotechnical model has a high level of confidence. } \\ & \text { Provides a good indication in the intrinsic spatial variability of the geotechnical } \\ & \text { characteristics. } \\ & \text { A comprehensive scope of analysis could be applied to well-defined geotechnical } \\ & \text { domains enabling the development of domain-specific mine design parameters. } \\ & \text { Variability or uncertainty in the geotechnical model would not significantly affect } \\ & \text { the economic viability of the project. } \\ & \text { Geotechnical model is based on in situ knowledge of the rock mass. } \\ & \text { Provides a reliable model of the intrinsic variability of geotechnical } \\ & \text { characteristics. Performance of the recommended design parameters have been } \\ & \text { verified through historical experience from neighbouring excavations and/or } \\ & \text { interim staged pit slopes. } \\ & \text { The design has been demonstrated to be practical and achievable. Variability or } \\ & \text { uncertainty in the geotechnical model would not adversely affect either the } \\ & \text { operational or economic viability of the project. }\end{aligned}$
Verified

Table 4 Percentage of geotechnical drilling to resource drilling showing range and mean values (after Haines et al., 2006)

\begin{tabular}{lc}
\hline Stage of Study & $\begin{array}{c}\text { Geotechnical Holes to } \\
\text { Total Resource Drilling }\end{array}$ \\
\hline Conceptual engineering (scoping) & $1.6-4.9 \%(2.8 \%)$ \\
Pre-feasibility (advanced scoping) & $4.0-10.6 \%(6.6 \%)$ \\
Feasibility & $5.0-24.0 \%(11.9 \%)$ \\
\hline
\end{tabular}


Read and Stacey (2009) provide qualitative guidance of geotechnical requirements for large open pit slope design in terms of different project stages. They consider: Conceptual (Level 1); Pre-feasibility (Level 2); Feasibility (Level 3); Design and Construction (Level 4) and Operations (Level 5). Requirements for the following have been qualitatively described:

- geological model

- structural model (major and fabric)

- hydrogeological model

- intact rock strength

- strength of structural defects

- geotechnical characterisation.

Data confidence levels are outlined for each of the above relative to the project study level.

\section{3 Newmont requirements}

Newmont has a Capital Effectiveness Program and a Stage-Gate approach is used for projects. Five stages are defined and are shown in Figure 1. The stages are similar to the levels outlined in Read and Stacey (2009) and in terms of more conventional terminology the following is applicable:

- Stage 1 Scoping study (establish if business case exists)

- Stage 2 Pre-feasibility (evaluate options)

- Stage 3 Feasibility (take forward 1 or 2 options from Stage 2)

- Stage 4 Detailed design

- Stage 5 Implementation and construction

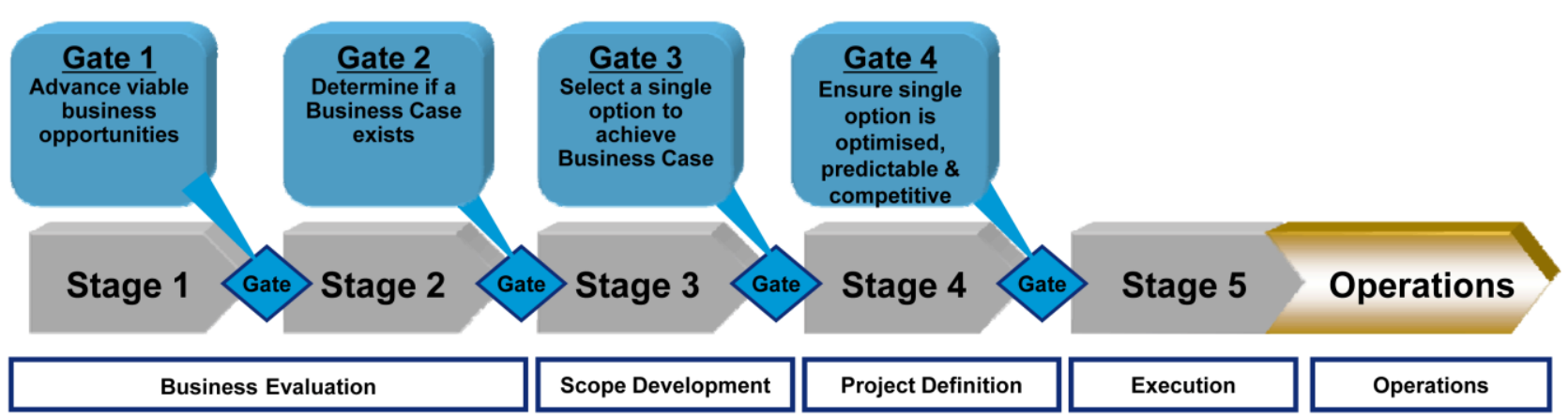

\section{Figure 1 Newmont Stage-Gate process}

Detailed deliverables and attributes are defined for each stage for each discipline (e.g. geology, mining, process, etc.). For geotechnical engineering the expectation would be to develop geotechnical models, conduct analysis and provide design and guidance appropriate to the study stage. The development of supporting geotechnical data collection programs is determined by the engineers conducting the geotechnical study.

\section{Geotechnical data requirements and issues}

Whilst the various sources referred to above provide invaluable guidance when designing geotechnical data collection programs, a large portion of engineering judgment is still required. There are a number of key issues that need to be considered for any geotechnical data collection program and these are briefly discussed below. 


\section{1 Data density}

The first question posed to the geotechnical engineer at the start of any project is: "How many holes do we need?" This also extends to other aspects of the data collection program such as strength testing, hydrogeological monitoring, etc. Unlike in the resource estimation field where statistical methods are applied to determine the required data density, very little exists in the field of geotechnical engineering and data collection programs tend to be reactive and tactical in nature.

There have been attempts by various authors (Steffen, 1997; Haile, 2004; Read and Stacey, 2009) to link data confidence to the resource process but this is essentially still qualitative and requires engineering judgement. Determining geotechnical data requirements as a proportion of cored resource holes is a valid approach, however, a more rigorous method of determining representative proportions is required. This will vary for different orebodies but a base methodology is required.

\section{2 Data collection timing}

There is often a reluctance to gather sufficient geotechnical data in the early stages (scoping or pre-feasibility) as there is a perception that the geotechnical data can be collected in later stages. The reality is that the mining engineers and designers often require geotechnical guidance early in the feasibility (Stage 3) study and cannot wait for the geotechnical program to be completed late during the stage. This can result in geotechnical guidance being issued based on limited geotechnical data and will often result in conservatism, design changes and rework later on.

By linking the geotechnical data collection program to the resource drilling program and ensuring that a representative proportion of cored holes are geotechnically logged to an appropriate level, it is possible to increase the level of geotechnical data in the early stages of a mining project. This is relatively easy for underground projects as drilling is focused on the orebody, for open pit projects additional geotechnical holes into the walls will be required. This will allow better decisions to be made during the pre-feasibility (Stage 2) study when various options are evaluated and can result in geotechnical guidance of a higher confidence level being provided to the mining engineers and designers earlier.

\section{3 Level of data collection}

Geotechnical data can be collected at different levels. For exploration and scoping studies (Stage 1), the collection of basic geotechnical data (rock quality designation (RQD), fracture frequency, field strength estimates, weathering and alteration) from cored holes is important and extremely useful. As the projects progresses into pre-feasibility (Stage 2 ) it is important to include detailed geotechnical domain or rock mass characterisation (RMC) logging which includes detailed descriptions of discontinuities and the collection of parameters for rock mass characterisation systems (Q system by Barton et al. (1974) and the RMR system by Bieniawski (1989)).

Orientated core and the collection of detailed data on individual discontinuities should form part of the data collection programs for Stage 2 and Stage 3, with the aim of progressively developing geotechnical models of increasing confidence. During these stages dedicated geotechnical holes may also be required to gather data not available from the geology holes. During Stage 2 a laboratory testing program should be developed.

As the project progresses into late Stage 3 and Stage 4, dedicated geotechnical holes to assess specific pit walls or underground main accesses and infrastructure are generally required. The level of data collection is also influenced by whether it is a green or brown field project. In the cases of a brown fields project, an extension of an existing orebody or cutback, there is usually some existing geotechnical data that can be used for the earlier study stages. 


\section{4 Data collection standards and management}

Often mines adopt the data collection procedures and standards of the consultancy conducting the study. In many cases consulting companies have developed specific approaches to data collection using modified rating systems which are different to standard methods available in the industry (e.g. ISRM field strength estimates). It is not uncommon to have different consulting companies working on a project at different stages and this often results in disjointed databases, re-interpretation and rework of geotechnical data.

Mining companies should establish consistent data procedures and standards that are based on accepted industry standards and are not consultancy specific. Data collection procedures should also be designed to capture base geotechnical data so that any of the main rock mass classification systems can be used rather than focusing on one system or modification thereof. This approach allows continuity of data and flexibility.

Geotechnical data is often stored in spreadsheets and whilst these are invaluable tools for data manipulation and analyses they are often unaudited, uncontrolled, easily corrupted and easily lost. To ensure data integrity and robust data storage, the use of spreadsheets as a database is discouraged and a proper database should be developed.

\section{$4 \quad$ Newmont Asia Pacific geotechnical data requirements}

Over the last few years Newmont Asia Pacific has been doing the geotechnical component of underground studies internally and this has allowed a move towards a more standardised approach, although there are legacy issues with existing databases. Informal guidelines have been developed to assist with the design of geotechnical data collection programs. These guidelines take into account that geotechnical environments vary and ranges rather than specific values are used. The amount of data required is linked to the resource-reserve process (Table 5) with the aim of taking advantage of drill holes that will be drilled at the required density to advance the project from a resources perspective.

The suggested approach is based on progressively gathering data, with early stages of a new project (Pre-Stage through Stage 1) focussed on gathering the basic geotechnical data. As the project advances (Stages 2 to 5), the level of geotechnical data collection increases (Table 5). Generally this level of detail is expanded to also include geotechnical domain or rock mass characterisation (RMC) logging and detailed structural logging of discontinuities utilising oriented core. Appropriate testing programs are developed in Stage 2 and may be expanded in subsequent stages, depending on the degree of variability shown in the initial testing program. If there is a large scatter in results additional testing will be conducted.

The percentages shown in Table 5 refer to the geotechnical logging requirements for the resource cored drill holes drilled in that stage. Additional specific geotechnical drill holes may be required to address data gaps and ground conditions in the area of proposed infrastructure away from the orebody. 
Table 5 Geotechnical data requirements per study stage

\begin{tabular}{|c|c|c|c|c|c|}
\hline \multicolumn{4}{|c|}{ Classification } & \multicolumn{2}{|c|}{ Geotechnical Guidelines } \\
\hline Newmont & $\begin{array}{c}\text { JORC } \\
\text { Resource }\end{array}$ & $\begin{array}{l}\text { JORC } \\
\text { Reserve }\end{array}$ & Stage & Logging Requirements & $\begin{array}{l}\text { Laboratory Testing } \\
\text { (per Lithology) }\end{array}$ \\
\hline $\begin{array}{l}\text { Potential } \\
\text { economic } \\
\text { mineralisation }\end{array}$ & - & - & 1 & Basic: $75-100 \%$ & - \\
\hline $\begin{array}{l}\text { Non-reserve } \\
\text { mineralisation }\end{array}$ & Inferred & - & 2 & $\begin{array}{l}\text { Basic: } 75-100 \% \\
\text { RMC: } 30-50 \% \\
\text { Structural: } 20 \%(\mathrm{~min})\end{array}$ & $\begin{array}{c}5 * \text { UCS, UTS and } \\
\text { elastic properties } \\
\text { Defect strength per } \\
\text { major sets }\end{array}$ \\
\hline $\begin{array}{l}\text { Reserve } \\
\text { conversion }\end{array}$ & Indicated & Probable & $3 / 4$ & $\begin{array}{c}\text { Basic: } 75-100 \% \\
\text { RMC: } 30-50 \% \\
\text { Structural: } 20 \% \text { (min) } \\
\text { Dedicated: as required }\end{array}$ & $\begin{array}{l}\text { Additional testing } \\
\text { depending on } \\
\text { variability } \\
\text { Triaxial if required }\end{array}$ \\
\hline Grade control & Measured & Proven & $\begin{array}{c}5 \text { and } \\
\text { operations }\end{array}$ & As required & As required \\
\hline
\end{tabular}

Notes: Hydrogeology and specific testing (stress measurements, raise bore index, soil Atterberg limits, etc.) to be conducted as required. Dedicated geotechnical holes required to address data gaps and for infrastructure.

Basic-RQD, fracture frequency, field strength estimates, weathering and alteration.

$\mathrm{RMC}$ - detailed descriptions of discontinuities and the collection of parameters for rock mass characterisation systems ( $Q$ and RMR).

Structural - Orientated core and the collection of detailed data on individual discontinuities.

\section{$5 \quad$ Project geotechnical data collection program examples}

Geotechnical data collection programs from a number of recent underground studies that have gone through the Newmont Stage-Gate process are briefly covered below.

\section{1 Mine-A}

A mature underground mine in a good quality rock mass using a sublevel open stoping (SLOS) method. Recently a number of studies have been conducted to investigate a deeper extension of the orebody and a new orebody that is situated below the existing mined orebody.

For the deeper extension of the orebody there was sufficient data from the upper portion of the orebody and RQD data from exploration holes for the Stage 1 and Stage 2 studies. Data collection for Stage 3 commenced in Stage 2. A high percentage of the resource drill holes had basic geotechnical logging and the guidelines outlined in Table 5 were applied for the Stage 3/4 study as shown in Table 6.

Table 6 Mine-A deeper extension geotechnical data program summary

\begin{tabular}{lccc}
\hline & Stage 1 & Stage 2 & Stage 3/4 \\
\hline $\begin{array}{l}\text { Geology holes geotechnical domain logging } \\
\text { Geology holes with detailed orientation and } \\
\text { structural logging }\end{array}$ & $\begin{array}{c}\text { Based on understanding of upper portion of } \\
\text { the orebody and geology holes with RQD } \\
\text { measurements }\end{array}$ & 75 \\
Strength testing & $\begin{array}{c}\text { Existing database } \\
\text { Stress measurements }\end{array}$ & Existing measurements & 3 (Ucoustic emission) \\
\hline
\end{tabular}


For the additional orebody situated below the currently mined orebody in the same lithologies, it was possible to make use of existing information initially and the project was fast tracked to a Stage 3/4 study. There was a focused effort to gather the detailed geotechnical data required (Table 7). Laboratory testing was conducted to confirm the results from previous testing programs.

Table 7 Mine-A additional orebody geotechnical data program summary

\begin{tabular}{|c|c|c|c|}
\hline & Stage 1 & Stage 2 & Stage $3 / 4$ \\
\hline Geology holes geotechnical domain logging & \multirow{3}{*}{\multicolumn{2}{|c|}{$\begin{array}{l}\text { Based on understanding of } \\
\text { adjacent mined orebody and } \\
\text { geology holes with RQD } \\
\text { measurements }\end{array}$}} & 132 \\
\hline Geology holes with detailed orientation and structure logging & & & 79 \\
\hline Strength testing & & & 27 (UCS) \\
\hline Stress measurements & \multicolumn{3}{|c|}{ Used existing measurements } \\
\hline
\end{tabular}

\section{2 Mine-B}

A narrow vein underground mine in a good quality rock mass using a sublevel benching method with pillars. The mine is situated in a moderate stress regime and additional stress measurements were conducted to confirm previous measurements. There was a progressive gathering of geotechnical data as the study progressed through the different stages, with most resource holes being geotechnically logged. Little difference was seen in the rock mass classification between stages 2 and 3 . The majority of the core was orientated and in excess of 5,000 structural measurements were made. Specific geotechnical holes were drilled to assess conditions in the vicinity of access infrastructure (Table 8).

Table 8 Mine-B geotechnical data program summary

\begin{tabular}{|c|c|c|c|}
\hline & Stage 1 & Stage 2 & Stage 3 \\
\hline Geology holes geotechnically logged & 7 & 20 & 37 \\
\hline Specific geotechnical holes & & & 11 \\
\hline Strength testing & & 19 (UCS) & \\
\hline Stress measurements & \multicolumn{2}{|c|}{ Existing measurements } & 2 (acoustic emission) \\
\hline
\end{tabular}

\section{3 Mine-C}

A narrow vein orebody consisting of several separate lodes in a highly variable rock mass. Basic geotechnical logging has been conducted on most resource drill holes and detailed geotechnical domain logging has been conducted for the hangingwall, ore-zone and footwall for the various lodes. Specific geotechnical holes were drilled to assess the conditions along the accesses. The strategy is to access the orebody and conduct further drilling and geotechnical data collection from underground drill platforms. Laboratory testing and stress measurements have also been conducted (see Table 9).

Table 9 Mine-C geotechnical data program summary

\begin{tabular}{lccc}
\hline & Stage 1 & Stage 2 & Stage 3 \\
\hline $\begin{array}{l}\text { Geology holes geotechnically logged } \\
\text { Specific geotechnical holes }\end{array}$ & 18 & 12 & Ongoing \\
$\begin{array}{l}\text { Strength testing } \\
\text { Stress measurements }\end{array}$ & 22 (UCS) & 4 \\
\hline
\end{tabular}


Adopting a strategic approach to the collection of geotechnical data by proactively addressing potential geotechnical risks, gaps and uncertainties will assist in achieving long terms goals. Such an approach will assist in making better decisions, managing geotechnical risk and reduce design conservatism.

When developing geotechnical data collection programs it is necessary to consider issues such as quantity of data, timing of data collection, level of data collection and data collection standards. Several authors have provided invaluable qualitative guidance on geotechnical data requirements for different stages of mining studies. There have been attempts to relate this to the resource-reserve process; however, this needs to be taken further. Currently engineering judgement and experience are key factors when designing geotechnical data collection programs and there is a need for more quantitative and objective methods of determining what data are required.

The approach being used by Newmont Asia Pacific has been outlined with some brief examples from recent underground studies. This approach is considered preliminary and further work is required to fully develop the process. The gathering of data from projects being advanced through various study stages will ultimately allow assessment and quantification of geotechnical data collection programs with the aim to developing a more rigorous approach.

\section{Acknow l edgements}

The authors would like to thank Newmont Asia Pacific for permission to publish this work.

\section{References}

Barton, N., Lien, R. and Lunde, J. (1974) Engineering classification of rock masses for the design of tunnel support, Rock Mechanics, Vol. 6, pp. 189-236.

Bieniawski, Z.T. (1989) Engineering rock mass classification, Wiley, New York.

Department of Industry and Resources (1997) Geotechnical Considerations in Underground Mines - Guideline, Department of Industry and Resources.

Department of Industry and Resources (1999) Geotechnical Considerations in Pen Pit Mines - Guideline, Department of Industry and Resources.

Haile, A. (2004) A reporting framework for geotechnical classification of mining projects, AusIMM Bulletin, AusIMM September/October 2004, pp 30-37.

Haines, A., Swart, A. and Kruger, A. (2006) Proactively mitigating geotechnical risks in open pit and underground mining, in Proceedings Strategic versus Tactical Approaches in Mining 2006, Australian Centre for Geomechanics, Perth, Australia, Section 27, $24 \mathrm{p}$.

Read, J. and Stacey, P. (2009) Guidelines for Open Pit Slope Design, CSIRO Publishing, Collingwood, 496 p.

Steffen, O.K.H. (1997) Planning of open pit mines on a risk basis, Journal of The South African Institute of Mining and Metallurgy March/April 1997, pp. 47-56. 